OPEN ACCESS

Edited by:

Karen Evans,

Commonwealth Scientific and Industrial Research Organisation

(CSIRO), Australia

Reviewed by:

Marjo Kristiina Vierros, United Nations University, Japan

Rachel Gjelsvik Tiller. SINTEF, Norway

*Correspondence:

Shona K. Paterson

shonakoren.paterson@brunel.ac.uk

Specialty section: This article was submitted to Marine Affairs and Policy, a section of the journal Frontiers in Marine Science

Received: 20 January 2020 Accepted: 22 April 2020

Published: 19 May 2020

Citation:

Paterson SK, Le Tissier M, Whyte $H$, Robinson LB, Thielking $K$,

Ingram M and McCord J (2020)

Examining the Potential of Art-Science Collaborations in the Anthropocene: A Case Study of Catching a Wave.

Front. Mar. Sci. 7:340. doi: 10.3389/fmars.2020.00340

\section{Examining the Potential of Art-Science Collaborations in the Anthropocene: A Case Study of Catching a Wave}

\author{
Shona K. Paterson 1,2*, Martin Le Tissier2,3, Hester Whyte ${ }^{2,3}$, Lisa B. Robinson ${ }^{4}$, \\ Kristin Thielking ${ }^{5}$, Mrill Ingram ${ }^{6}$ and John McCord ${ }^{7}$
}

\begin{abstract}
${ }^{1}$ College of Business, Arts and Social Sciences, Brunel University London, Uxbridge, United Kingdom, ${ }^{2}$ International Project Office, Future Earth Coasts, MaREI, ERI, University College Cork, Cork, Ireland, ${ }^{3}$ MaREI, the SFI Research Centre for Energy, Climate and Marine, Environmental Research Institute, University College Cork, Cork, Ireland, ${ }^{4}$ School of Art and Design, East Carolina University, Greenville, NC, United States, ${ }^{5}$ Department of Art and Design, University of Wisconsin-Stevens Point, Stevens Point, WI, United States, ${ }^{6}$ Center for Integrated Agricultural Systems, University of Wisconsin-Madison, Madison, WI, United States, ${ }^{7}$ Coastal Studies Institute, East Carolina University, Wanchese, NC, United States
\end{abstract}

There is a disconnect between ambition and achievement of the UN Agenda 2030 and associated Sustainable Development Goals that is especially apparent when it comes to ocean and coastal health. While scientific knowledge is critical to confront and resolve contradictions that reproduce unsustainable practices at the coast and to spark global societal change toward sustainability, it is not enough in itself to catalyze large scale behavioral change. People learn, understand and generate knowledge in different ways according to their experiences, perspectives, and culture, amongst others, which shape responses and willingness to alter behavior. Historically, there has been a strong connection between art and science, both of which share a common goal to understand and describe the world around us as well as provide avenues for communication and enquiry. This connection provides a clear avenue for engaging multiple audiences at once, evoking emotion and intuition to trigger stronger motivations for change. There is an urgent need to rupture the engrained status quo of disciplinary divisions across academia and society to generate transdisciplinary approaches to global environmental challenges. This paper describes the evolution of an art-science collaboration (Catching a Wave) designed to galvanize change in the Anthropocene era by creating discourse drivers for transformations that are more centered on society rather than the more traditional science-policy-practice nexus.

Keywords: transdisciplinarity, sustainability, art-science, Anthropocene, SGD14

\section{INTRODUCTION}

The world is at a turning point for sustainable development and there is an evolving need to identify and enact new pathways to action in the face of constantly shifting biophysical and social realities (Randers et al., 2018). The aspirational and collective nature of the UN Agenda 2030 and its Sustainable Development Goals (SDGs) (United Nations, 2015) has been used as a central tenet 
to inspire numerous meaningful and impactful transdisciplinary partnerships, including between art and science actors (Brennan, 2018; van der Vaart et al., 2018). The SDGs have been used to galvanize, among others, the role of youth and innovation (Bastien and Holmarsdottir, 2017), engagement with industry and business (Scheyvens et al., 2016; Weber, 2018), sports (Lemke, 2016), and gender equality (Fredman et al., 2016). This suggests that actors within both community and political spheres are attempting to take advantage of the holistic and optimistic appeal of the SDGs to stimulate social action (McAfee et al., 2019). In fact, there is a growing recognition that overall achievement of the SDGs depends not only upon responsible economic development administered through the lens of environmental sustainability, but perhaps more significantly, through enhanced social inclusion and justice (Ensor et al., 2018; Patterson et al., 2018; Fleming et al., 2019). The literature is beginning to reflect a more systematic consideration of social justice implications of climate change responses at national and subnational levels, including differential abilities to adapt (Paavola and Adger, 2006; Adger et al., 2017) as well as the need to ensure that those least able to influence the process but often most affected are heard (Fleming et al., 2019).

Despite this recognition, there is a gap in the current conceptualization of the UN Agenda 2030 and the SDGs and implementation at scale (Le Blanc, 2015; Stevens and Kanie, 2016; Stafford-Smith et al., 2017; Blythe et al., 2018; Scherer et al., 2018), across the Global North-South binary (Iqbal and Pierson, 2017; Hayward and Roy, 2019; Horner and Hulme, 2019) and especially when framed within the concept of the Anthropocene (Lim et al., 2018). This gap has two origins; (i) the knowledge and science needed to achieve the SDG targets and indicators and (ii) the engagement of the whole public in SDG delivery. Both of these origins are easily demonstrated in coastal and ocean systems: systems that are under ever increasing pressure from direct pollution and eutrophication, climate change, and fishing and aquaculture (Borja et al., 2017; Visbeck, 2018). Despite continued discourse around the importance of these spaces, epitomized by SDG14:Life below Water, little traction has been gained when it comes to shifting behaviors or resonating with society on a broader scale (Cormier and Elliott, 2017; Fleming et al., 2019). Recent politically focused engagement activities have shown that SDG14 is almost universally considered the least important of the SDGs (Custer et al., 2018). These results were derived from a questionnaire sent to elected politicians, bureaucrats, non-profit and humanitarian executives, and business leaders from 126 lowand middle-income countries in South and Central America, Africa, Europe, and Asia. They demonstrate a clear severing between the rhetoric of scientific research agendas (ICSU and ISSC, 2015; Plag, 2018; Visbeck, 2018) and reality around the lack of a perceived political importance (Custer et al., 2018). This is despite the fact that fish and seafood are a primary source of protein for more than one billion of the poorest people on Earth (Huelsenbeck, 2012; Béné et al., 2016) and the goods and services from coastal and marine ecosystems being estimated to contribute about $\$ 2.5$ trillion (USD) to the global economy each year with a total asset base of at least $\$ 24$ trillion (USD) (Hoegh-Guldberg, 2015). For instance, Europe’s coastal regions are home to 214 million people and generate $43 \%$ of EU GDP, and the blue economy is regarded as a growth sector, with opportunities both in established sectors like tourism and shipbuilding, and in emerging areas like ocean energy or the blue bio-economy (European Commission, 2019). Yet, coastal landscapes are under considerable pressure and change, for instance, from sea level rise changing unalterably the physical, social and economic geography of coasts (Ramesh et al., 2015) or the marine plastic issue (Haward, 2018; VillarrubiaGómez et al., 2018). This disconnect is further illustrated by a number of SDG interlinkages tools and national governmental documents that either fail to feature SDG14 or coastal and ocean spaces, such as UNEP's Frontiers 2018/19: Emerging Issues of Environmental Concern report (UNEP, 2019), or show poor reporting across all environmental SDGs (e.g., Sachs et al., 2018; Villarrubia-Gómez et al., 2018).

In a time of global environmental change and uncertainty, knowledge acquisition, transfer, and application for global societal change is critical, and a call for innovation, including arts and the humanities, to foster action at all levels of society forms part of the United Nations Decade of Ocean Science for Sustainable Development (2021-2030) (Claudet et al., 2020). This paper examines a process to build an inter- and transdisciplinary art-science collaboration to create such opportunities to elucidate a mechanism that can galvanize change by creating discourse drivers for transformations that are more centered on society rather than the more traditional science-policy-practice nexus. A case-study of an iterative project, Catching a Wave, designed to demonstrate the co-design potential of ocean and coastal sustainability while providing levers for both cultural identity and innovation is presented. In addition, the process of transdisciplinarity to create such transformational pathways to impact are also examined. Finally, a critical assessment of the potential of catalyzing social change through an integrated art-science approach is discussed.

\section{CONTEXT FRAMING}

Human pursuit of coastal sustainability in the Anthropocene requires transformative social and economic pathways that navigate toward sustainable development co-created with the intended beneficiary communities (Pelling et al., 2015; Future Earth Coasts, 2018). There is increasing awareness that existing assessment processes that monitor the status of environmental and societal components of coastal systems cannot on their own deliver the knowledge for transformations to more sustainable pathways of coastal use (Ajzen, 1985; Benham and Daniell, 2016; Marques et al., 2016; Comte et al., 2019). Problem to solution formulation is not simply an issue of multi-disciplinary approaches but must account for social and cultural values, norms, and priorities that differ greatly based on a variety of issues (Leiserowitz et al., 2006; Jefferson et al., 2015; Bennett, 2016; Mayer et al., 2017). This variation is also reflected in the ways that people learn and communicate knowledge, shaped by new forms of communication (Shi et al., 2016; Zareie and Jafari Navimipour, 2016), especially around climate and sustainable 

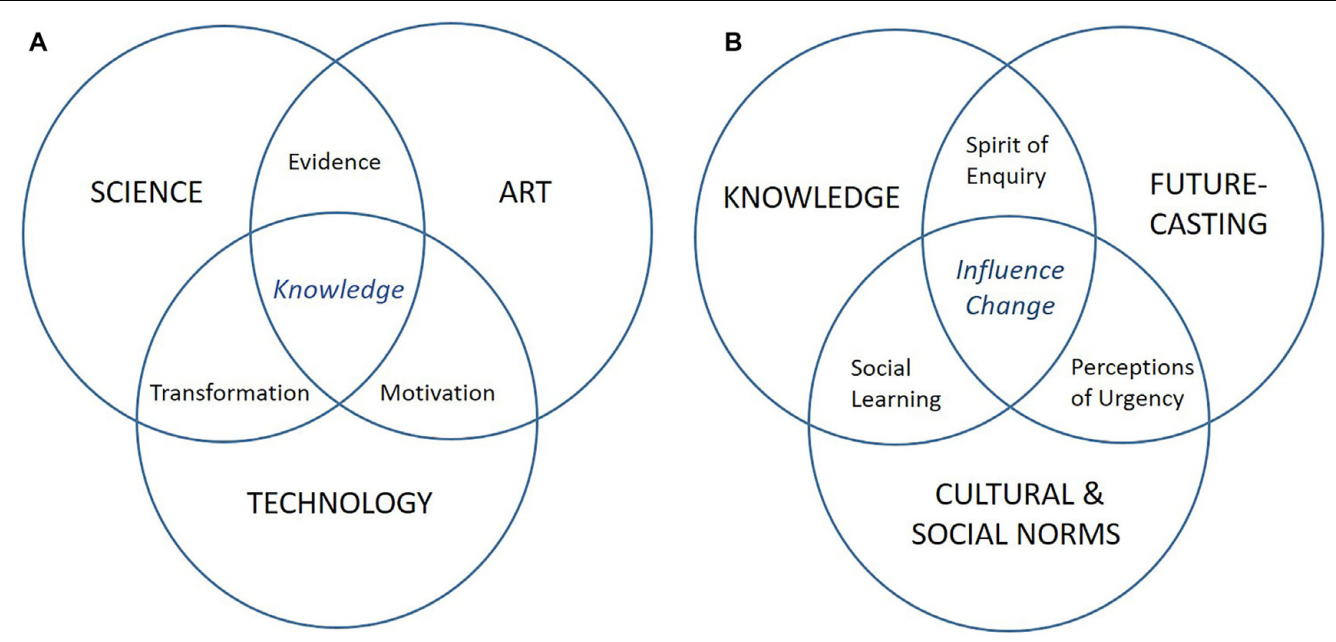

FIGURE 1 | (A) Both arts and sciences increasingly employ technology as part of their methodologies but by working collaboratively the opportunity to combine motivational aspects of decision making by individuals and society promoted by art with the transformations that science seeks through the persuasive 'power' of facts is likely to lead to a deeper held knowledge that reflects cognitive with emotion and intuition in decision making (49). (B) Both knowledge and 'imagination' to 'see' better futures or understanding of the past combine to manifest more impactful and meaningful avenues for enquiry and potential innovative solution spaces that art, science, or technology could achieve alone. When coupled with the norms and cultural values held within society, knowledge can be instrumental in enabling deeper, social learning that allows for new behaviors to be acquired creating a negotiated space that allows for change (70). These elements all are necessary to catalyze the large-scale shifts in behavior across society that are needed to enable sustainability.

development issues (Ballantyne, 2016; Moser, 2016). This reality means that knowledge in combination with learning, both social and individual, is critical in catalyzing the sense of urgency necessary to influence change (Figure 1) (van Mierlo and Beers, 2018; Goyal and Howlett, 2019). Therefore, in order to spark global societal change toward future sustainable pathways at all scales, the mechanisms through which science, knowledge and social learning are employed and engaged with also have to be more responsive to social differences and inputs (Ensor and Harvey, 2015; Cummings et al., 2018; Wehn and Montalvo, 2018). Existing processes need to respond to a variety of ways of knowing that lead to different contexts of application requiring new processes to integrate and engage with these differences from the start (Brugnach and Ingram, 2012; Hawkins et al., 2015; Eldred, 2016).

In this paper, transdisciplinarity is taken as providing a framework that transcends disciplinary boundaries to develop holistic and transformative solutions where the outcome extends beyond interdisciplinary approaches to create something completely new providing space for social transformations as well as governance ones (Defila and Di Giulio, 2015; Klenk and Meehan, 2017; Schneider et al., 2019; Norström et al., 2020). Such approaches can embed social justice at their core and also allow for geophysical, ecological, philosophical, cultural, and emotional connections to ocean and coastal spaces to be realized at different scales (Brown, 2015; Olsen et al., 2016; Irwin et al., 2018). They also embrace concepts such as co-production in a practical rather than an analytical sense, focusing on the intentional act of engaging non-scientific actors in the process of scientific knowledge production, which has increased this responsiveness (van der Hel, 2016). Examination of such enabling mechanisms, and potential innovations and transformations to existing social structures, can shed light on how public opinion is shaped, how perceptions are formed across diverse areas in society, and how to mobilize change across scales (Leiserowitz et al., 2006; Miller et al., 2014). This can provide pathways to increase the impact factor of science and knowledge through traditional and non-traditional communication routes (Reed et al., 2010).

\section{Art-Science Collaborations}

Art and science literature make clear that both 'disciplines' share a common motivation and goal to understand and describe the world around us (Sleigh and Craske, 2017), and are engaged in concepts of reflection across all elements of society to effect changes in behavior in individuals and society. In addition, both art and science provide avenues for enquiry and communication, impacting different audiences through the generation of a multiplicity of resonate narratives (Chabay, 2015). Art, in its many and varied forms, has the liberty and ability to generate shifts in social perceptions and behaviors in ways that science and data alone currently do not (Pearce et al., 2003; Eldred, 2016; Brennan, 2018), providing a complementary pathway for engagement. However, despite common goals, more and more literature has been generated around how the increasingly engrained status quo of disciplinary divisions across academia and society is actively contributing to this separation (Leach, 2005; Sleigh and Craske, 2017). It has been postulated (Trondle et al., 2019) that combined collaborative arts and sciences projects can enhance transformations by encouraging decision making that engages with emotion and intuition as well as cognition as a motivation behind change (Soosalu et al., 2019). Numerous benefits of bringing together the methodologies and practices of science and technology with art in its many forms in a transdisciplinary cross-over approach can be identified. These 
include the creation of participatory and discourse spaces that generate evidence and enable transformation in practice (Fischer, 2006; Oliver and Boaz, 2019) as well as shared and negotiated understanding of the meaning and implications of existing knowledge (Born and Barry, 2010; Gibbs, 2014) and increased innovation in knowledge transfer (Cornell et al., 2013) (Figure 1).

Although challenges to the great divide of art and science, hallmarked in C. P. Snow's 1956 model of "two cultures," are not new (Snow, 1956), art-science collaborations have experienced a surge of interest in recent years (Born and Barry, 2010; Trondle et al., 2019). Malina (2001) used the term 'new Leonardos' in his effort to capture ways that he saw people charting new professional territory synthesizing art, science and technology. Describing the information arts, Wilson (2002) heralded an "essential rapprochement" between "two great engines of culture." Since then, across a spectrum of sectors and activities, the involvement of artists in the production of science and technology is no longer rare, although it is far from routine. Collaborations have enabled technological innovation (Broadhurst, 2007; Eldred, 2016), urban environmental rejuvenation (Ingram, 2014; Whitehead, 2018), data visualization (Cox, 1991, 2004; Born and Barry, 2010; Woodward et al., 2015), new models for education and work (Ghosh, 2005; Gurnon et al., 2013; Hawkins et al., 2015), the role of technology in society (da Costa and Philip, 2008) and even national competitiveness (Huggins and Clifton, 2011). Key examples that can be drawn on with respect to SDG14 include public discussion on the impacts of sea-level rise and changing ocean health on coastal and island communities (Ingram, 2014; Straughan and Dixon, 2014; Brennan, 2018), ocean ice (O'Connor and Stevens, 2018), and the impacts of ocean plastics (Carnell et al., 2020). Some of these collaborations are well established, such as the United Kingdom-based Cape Farewell project that has focused on climate change and the Arctic with the aim of fostering a cultural discussion (Ingram, 2011).

\section{ENACTING A TRANSDISCIPLINARY ART-SCIENCE PARTNERSHIP}

In the context of the work described here, principles of transdisciplinarity were inculcated in the working of the project team and the design and implementation of workshops. For workshops, participation from outside of academic circles, including participants from outside of the research realm who bring additional worldviews and experiential knowledge necessary to address complicated and pressing social and environmental problem (Carew and Wickson, 2010; Defila and Di Giulio, 2015; Klenk and Meehan, 2017), was actively encouraged. For transdisciplinarity to achieve its own stated goals, there is a need to move beyond the inclusion of nonscience disciplines, and particularly the arts, as 'add-ons' to accomplish outreach and communication goals (Brandt et al., 2013; Norström et al., 2020). Instead, integrating these disciplines into all aspects of the design, implementation and outcomes of projects can provide the necessary pathways to break through barriers of language to bridge between stakeholders across science, society and politics communities (Popa et al., 2015). Art is a means for stakeholders and knowledge providers, whatever their discipline, to discover their own meaning and new ways to convey their understanding to others, and provide an open platform to juxtapose potentially conflicting and contradictory perspectives.

Transdisciplinarity provides an opportunity to capture the creativity of art to bring cultural capital to science in the context of Snow's (1956) two-cultures debate (Sleigh and Craske, 2017) to address the increasingly complex challenges confronting sustainable development (Bernstein, 2015; Zafeirakopoulos and van der Bijl-Brouwer, 2018), currently framed by the UN 2030 Agenda (United Nations, 2015). This re-imagination is rooted in Barry et al.'s efforts to identify art-science collaborations through the lens of three logics of interdisciplinarity: accountability, innovation, and ontology (Barry et al., 2008; Born and Barry, 2010) where (i) accountability refers to the way in which scientific research is increasingly required to make itself accountable to society, (ii) innovation draws attention to scientific research needing to fuel industrial or commercial innovation and economic growth, and (iii) ontology discusses provoking change in both the object(s) of research, and the relations between research subjects and objects.

The ontological logic is the most critical in this construction, highlighting the reality that some art-science initiatives are focused on altering existing ways of thinking about the nature of art and science, as well as with transforming the relations between artists and scientists and their objects and publics (Born and Barry, 2010).

\section{Catching a Wave Case Study Concept Development}

Catching a Wave $(\mathrm{CaW})$, an iterative sea-level rise multi-media installation, has brought together a research consortium from four universities based in the United States, United Kingdom, and Ireland. CaW was deliberately conceptualized to act as a catalyst for constructing a transdisciplinary approach for shifting individual and collective mind-sets toward action for more sustainable oceans and coasts and the people who live, work, and interact within these spaces. Focused on five SDGs; SDG13: Climate Action and SDG14: Life below Water, SDG3: Good health and wellbeing; SDG15: Life on Land; and SDG17: Partnerships for the Goals. CaW was designed to increase awareness and resonance of the SDGs and oceanscapes with multiple audiences. While CaW specifically set out to transform the way in which actors, stakeholders, and society interact with ocean and coastal spaces, the process of message development has remained dynamic and driven by an iterative co-design process. Using the models described in Section "Context Framing" (Figure 1), CaW has coupled elements more aligned with knowledge generation in natural systems with technological applications and innovative practices to enable more effective translation of actions into products that seek to influence society and society interaction (Figure 2). CaW can therefore act as a translation lens for both knowledge and ways of knowing that 


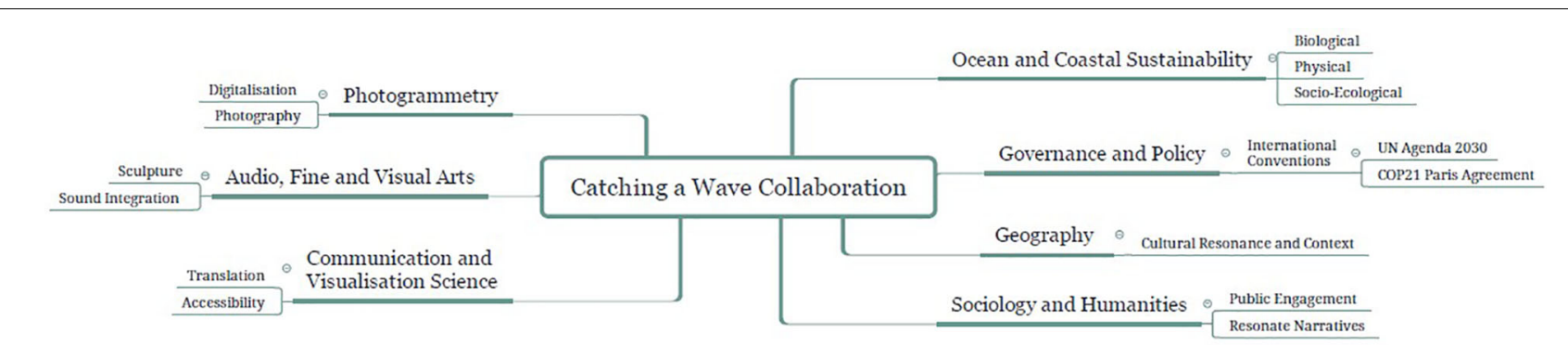

FIGURE 2 | The architecture for a transdisciplinary collaboration for shared knowledge generation elements that underpins CaW to reflect both cognitive and emotional elements that can support societal transformation for sustainability. The collaboration acts as an integrating interface between both disciplines of enquiry and communication technologies to develop products - in this case artistic representations of waves- to encourage and enable conversations between holders of different facets of knowledge, opinions and perspectives that might not otherwise take place, or would take place in a contested setting.

may help to catalyze both the spirit of enquiry as well as social learning over time.

\section{Technical Development and Innovation}

Initially conceived to create an artifact that would embody an exact moment in time, CaW focused on using "captured" waves made of glass in sculptural installations designed to communicate, in a novel way, information about climate change, sea level rise, ocean health and to publicize ocean-related research. These glass artifacts were to visually communicate the complexity of what is happening in a single wave at a single moment of time, and make a connection for the viewer to the intricacy of what was happening, on the surface and internally, in that wave ${ }^{1}$.

Each wave was generated in a wave tank at the Coastal Studies Institute in Wanchese, NC, United States and photographed from a half-dome 360 degree rig of 16 Nikon D810 36.3 MP full frame digital SLR cameras, capturing as many wave surfaces as possible from a variety of angles. High-speed sync triggers were installed on cameras to synchronize the shutters to within $1 / 1000$ th of a second to ensure the cameras fired at precisely the same moment. Agisoft Photoscan Pro modeling software was used to reconstruct the location of the photographs and create three-dimensional (3D) point clouds made up of common points in each picture, resulting in one composite $3 \mathrm{D}$ digital image (Figure 3). Transparency and motion issues, caused by the nature of water itself, were solved by spreading sawdust on the water's surface. The sawdust provided the needed contrast and tracking surface for the $3 \mathrm{D}$ rendering software. This digital output was subsequently used to produce a $3 \mathrm{D}$ printed replication of the photogrammetrically captured wave. A flexible silicone mold was made of the $3 \mathrm{D}$ printout. Wax was poured into the silicone mold creating a wax positive of the $3 \mathrm{D}$ printout from which an investment mold was made (mixture of plaster and refractory materials, i.e., silica and grog) into which was placed cold glass (cullet), small colored powders and grains of glass (frit) to add colors that resembled water and sheet glass with text and images printed with glass enamels. The molds filled with this glass mixture were placed into an electric kiln and heated slowly to $1,460^{\circ}$ Fahrenheit $\left(794^{\circ}\right.$ Celsius) for $40 \mathrm{~min}$ then annealed at $900^{\circ}$

\footnotetext{
${ }^{1} \mathrm{CaW}$ video.
}

Fahrenheit $\left(482^{\circ}\right.$ Celsius) to remove stress and to make sure the glass is the same temperature at the core and at the surface. The glass is then cooled slowly in three stages to prevent cracking. After removing the mold from the kiln, the investment mold material is removed, and the glass polished with an eight step process (using a series of diamond grits, smoothing materials) until it is clear enough to see into the interior of the wave. To make the smaller waves the glass castings were cut into about 912 smaller pieces and each polished so that one can see into the interior of the glass.

\section{Message Development and Experience Contextualization}

The initial concept of using waves as focal points to generate an emotional and behavioral reaction to ocean and coastal spaces was introduced during a pilot workshop at the Society and the Sea Conference in 2018 (Figure 4). The workshop engaged 20 self-selected conference participants whose interests were aligned to the conference theme of achieving ocean sustainability (specifically in the context of exploration of the value of the ocean and how that can be recognized, communicated and harnessed to contribute to the health, wealth and wellbeing of society). The purpose of the workshop was to engage with a community of interest from diverse disciplines, which included natural and social scientists as well as from the arts and humanities, who could share experiences and provide $\mathrm{CaW}$ with opinions on how to evolve art-science integration. This workshop blended both interactive (on-line tools Slido and Padlet and semistructured discussions focused on linkages and communication, breaking down barriers and opportunity as part of a finding solutions exercise) and PowerPoint and video presentations centered on SDG14. Small hand-sized waves were distributed amongst the participants as a reminder of the workshop and a novel way of staying connected to the project. From the discussions several key messages emerged with respect to how an art-science collaboration could make Sustainable Development Goal 14 Life Below Water more prominent on peoples' agenda (Future Earth Coasts, 2020):

(1) One-size-fits-all to communicate science to other communities/disciplines does not work but requires a suite of media platforms to be used, and which allow others 

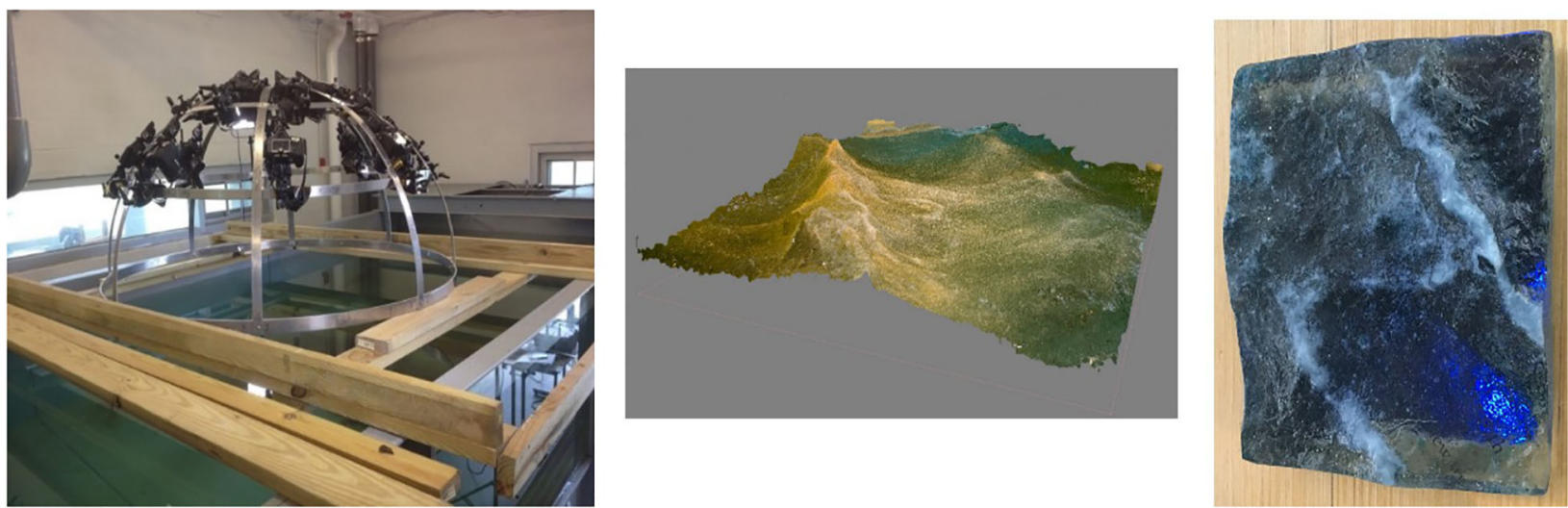

FIGURE 3 | The process of wave capture from technical through digital and physical forms (i) Camera rig designed for photographing the water, (ii) the resulting digital image of captured wave and (iii) a glass wave from above.
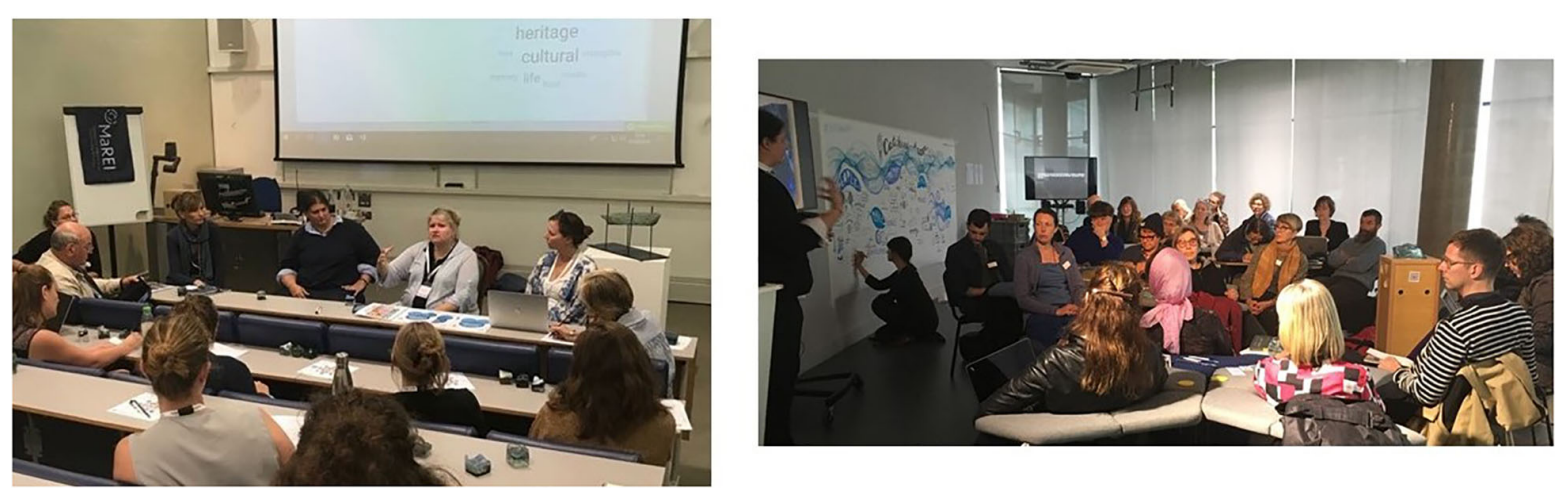

FIGURE 4 | Interactive CaW interactive workshops from (i) Society and the Sea, Greenwich (2018) and (ii) Art in the Anthropocene, Dublin (2019).

to become part of the conversation between specific events. However, it is important to exercise care when introducing 'new' types of media (e.g., Slido and Padlet) that could become a barrier to expression.

(2) Ensuring that workshops provide opportunity for participants to engage in the topic through a lens of their own work and experiences, rather than solely through the lens of the project being presented, is important.

(3) There was a proof-of-concept validation of the approach taken by the CaW project, including the use the glass waves, as a medium to engage and nourish conversations between disciplines that would not normally take place.

(4) The participants reinforced a need to interpret transdisciplinarity as an extension of interdisciplinarity to include stakeholders as practitioners of research (Klenk and Meehan, 2017) with a view to invoke the issue of social inclusion to ensure that those least able to influence political and social processes but often most affected are heard.

These outcomes from the first workshop informed a second iteration implemented during the Art in the Anthropocene (AiA) Conference in 2019 where a $\mathrm{CaW}$ installation was coupled with an interactive workshop run twice to accommodate the demand to participate (Figure 4). The two 2-h workshops were delivered at the Science Gallery, Dublin, to a total of 82 selfselected participants from principally artistic and social science backgrounds, but also included youth (below 16 years age), business and civil society. Given the nature of the conference, and un-like the Society and Sea conference, the background of the audience was not primarily environmentally, and coastal/sea, focused but more strongly focused on questions that concern the sustainability of the planet from a societal perspective (Catching a Wave, 2019). Using feedback from the first workshop and in an attempt to adapt the workshop to engage with a different audience $\mathrm{CaW}$ made a number of changes to the organization of the workshop, namely:

(1) To broaden the discursive space, this workshop series focused around the five pillars (5Ps) of Agenda 2030 - people, prosperity, planet, peace and justice, and partnership. These pillars have been used in the UN Agenda 2030 (2) to recognize the interlinked and integrated nature of the SDGs and the interconnectedness of factors and interventions that influence human development outcomes. 
(2) The waves were approximately four to five times larger than the previously used hand-sized ones and displayed on five individual pedestals creating a space whereby the workshop participants were physically sitting amongst the installation during the workshop and being fully emerged in the exhibit

(3) The waves were modified to include;

(a) Images and text relating to ocean health embedded into the glass waves fusing them so that they folded into the wave but remain legible through the polished sides of each wave and,

(b) Sounds, both human and non-human, were incorporated to each installation piece. Sound, such as waves, dune birds, oysters clicking, and voices of both children and adults created an additional avenue to provide local context for the audience to connect to, as well as provoke an emotional connection to the ocean.

(c) Participants were encouraged to leave any comments, observations, and thoughts behind on post-it notes on any of the pedestals.

(d) As well as the installation, small hand-held waves were handed to participants as they arrived and used as an entry point to engage individually with participants on their background, expectations from the workshop and perspectives on sustainability challenges facing coasts and seas before and after the workshop.

(e) A QR code that linked to the CAW website was sandblasted onto the bottom surface of hand-held waves to promote longer-term connection to the project.

(4) The main body of the workshop consisted of a series of video presentations to represent each of the 5Ps and each video was immediately followed by a facilitated discussion on how the video linked to and juxtaposed with individual perceptions to the challenges of coastal and marine sustainability.

(5) During both workshops, a graphic artist made a recording of the conversations by visually articulating how the discussions and conversations were formed, and highlighting those aspects of coastal and marine sustainability participants considered most important and urgent, as well as mechanisms for learning (Figure 5).

From the CaW side, the intent of workshop discussion was to explore how an art-science partnership could engage with nonscientist audiences to recognize and emphasize what is perceived by the science community as a critical state of the world's oceans (IPCC, 2019) through a transdisciplinary approach. However, from the workshop participants the discussion revolved around how collaborative efforts such as CaW should work internally to extend beyond interdisciplinarity and achieve a transdisciplinary approach, as well as the need to be flexible and agile in terms of project goals and objectives. The messaging also from the workshops elucidated an increasing desire amongst researchers from more artistic disciplines for optimistic and empowering efforts that unite communities and populations rather than feardriven efforts that have a more dividing response. In general, it became apparent that whilst natural sciences are comfortable with the drive of the UN Agenda 2030 and the SDGs, there is strong criticism of these initiatives from other disciplines and a perceived lack of societal focus in implementation (Liverman, 2018; Swain, 2018). Outcomes from discussions suggested that:

(1) Trying to set a broader context of SDGs to meet the composition of the audience had the unintended outcome of losing clarity around the place of sciences in the context of the art.

(2) Achieving a balance of synergies and trade-offs between environmental change and impacts on society is challenging.

(3) There is a need to lead with the requirement for a transdisciplinary approach to justify and validate a wider context rather than a focus on specifics (e.g., SDG14).

(4) There are currently weak procedures to assess the artscience collaborative process to evaluate the impact of transdisciplinarity endeavors and their behavioral influences on diverse communities of interest.

Overall, there was validation of the proof of concept in that participants were strongly encouraging that the blending of science and art used by the $\mathrm{CaW}$ project presented considerable opportunity to lead to more meaningful engagement across different communities, but the collaboration needed to be widened to ensure transdisciplinarity.

\section{Engagement and Impact}

The overall goal of $\mathrm{CaW}$ has adapted into the development of a process of engagement and collaboration that enables moving beyond accounting for impacts on coastal and ocean systems to instead address concerns around closing knowledge gaps to specifically empower those who are often left out of the management and usage conversation for a variety of reasons. $\mathrm{CaW}$ has therefore been influenced by the desire to contribute to providing new tactile and other sensory experiences that connect recognized and disenfranchised stakeholders to ocean and coastal spaces, specifically shaping that experience with, and for, those likely to be impacted by changes to the system.

With each iteration, CaW has demonstrated learning within the project team across social, ecological, and physical aspects of the oceans while providing space for both cultural identity and technological and social innovation. This approach has allowed the CaW project to move beyond a 'service mentality' where science and art products are produced in isolation into the development of an integrated collaboration space that can demonstrate the power and synergies between these disciplines. A critical review of this learning gleaned from the workshops has provided an opportunity for the evaluation of the potential knowledge generation of $\mathrm{CaW}$ using both the framework discussed in Figure $\mathbf{1}$ as well as the ontological logic of interdisciplinarity previously presented (Barry et al., 2008; Born and Barry, 2010).

Barry et al. (2008)'s ontological logic enables the exploration of how CaW processes of scientific and technological production; in the process of creating the glass waves, for example, altering ways of thinking about the relationships between science and art and 


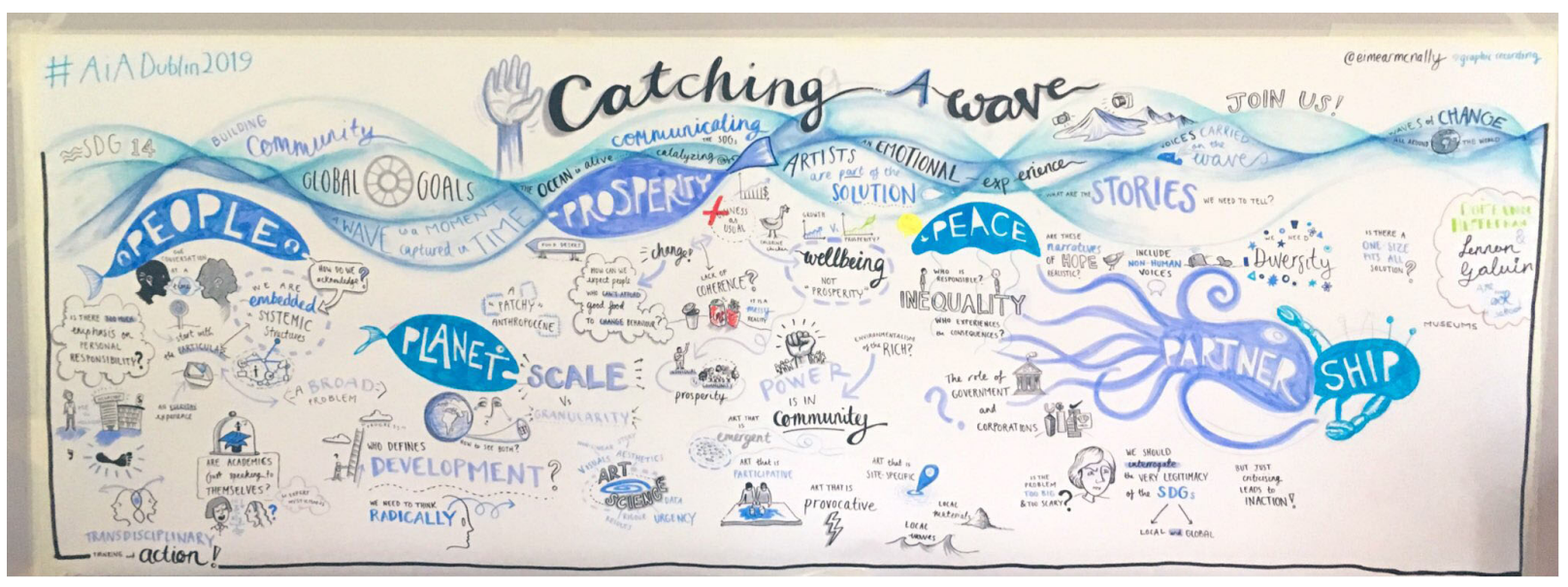

FIGURE 5 | A graphical recording of the CaW interactive workshop at the Art in the Anthropocene Conference 2019 that captured conversations and observations made by attendees. Graphic Artist: Eimear McNally.

the objects they produce. A co-benefit from a shift in behavioral responses across different sections of society toward action for more sustainable oceans and coasts would be to reduce gaps in their viewpoint of the UN Agenda 2030 and the SDGs. To date, CaW's engagement has been largely limited to inherently scienceart audiences. This has been critical to both message development and anchoring of the work in local contexts. However, future events are being planned to target a range of different audiences. This will provide a greater opportunity to increase accessibility of outputs to different stakeholder groups and audiences allowing more avenues for impact across scales. Increased engagement is expected to strengthen the evidence and co-designed elements of CaW outcomes.

Technology and artistic innovation have played a large role in CaW's development as the project's message has matured from pathways to sustainability toward a vision with a stronger social justice influence. This has included the development of a website ${ }^{2}$ and use of social media to promote art-science messaging. The inclusion of audio, especially the voices of coastal inhabitants, has provided an additional avenue to anchor the work with personal experiences that describe different aspects of human connection to ocean and coastal spaces. In retrospect, this anchoring has provided profound influence for the project's own transformation by allowing actors in society to describe the types of knowledge gaps that exist within their own decision making and spheres of influence.

\section{CHALLENGES AND OPPORTUNITIES OF COLLABORATIONS IN THE ANTHROPOCENE}

While case studies like CaW can demonstrate the importance of not only transdisciplinary approaches for knowledge generation, they also raise many questions around who is generating that

${ }^{2}$ www.catchingawave.org knowledge, and how it is utilized. As social justice becomes a more systemic consideration for the SDGs (Freistein and Mahlert, 2016; Scoones et al., 2020), questions around power and influence over decision making become more pertinent (Bexell and Jönsson, 2017; Fukuda-Parr and McNeill, 2019). A series of multiple, often contested, pathways for guiding societies toward sustainability have been identified with controversies emerging between weak and strong sustainability (Dietz and Neumayer, 2007; Neumann et al., 2017), between techno-centrism and ecocentrism (Audet, 2014), between adaptation and transformation (Dow et al., 2013) and between reformist and revolutionary positions (Geels, 2011; Geels et al., 2015). This contested space, all argued from a position of evidential strength, highlights the need for a more negotiated process that can develop clear bargained objectives where, both at individual and collective scales, the many technical and/or technocratic solutions that are presented by disciplines can be evaluated and re-evaluated to determine a positive way forward.

Art-science collaborations offer a way to structure the discussions that arise at each decision point on the sustainability route. Art offers a way of creating a platform that allows different perspectives and different conversations to take place in order to negotiate or bargain which pathway or which approach society may want to adopt in that journey. In this way, the model presented in Figure 1A becomes a series of feedback systems for potential persuasion as well as knowledge generation (Figure 6) that is underpinned by the constructs in Figure 1B. The feedback loop provides a mechanism for the needs of society to influence the knowledge that is being generated by art, science and technology or any combination of the three. Therefore, this re-imagined space creates a strong opportunity to fully engage with issues raised under a social justice lens in the future as well as provide an avenue for society to actively define knowledge needs. Acknowledging that collective action and behavioral change, at all scales, is strongly dependent on networks and flows of information between individuals and groups and the relationships and patterns of reciprocity and 


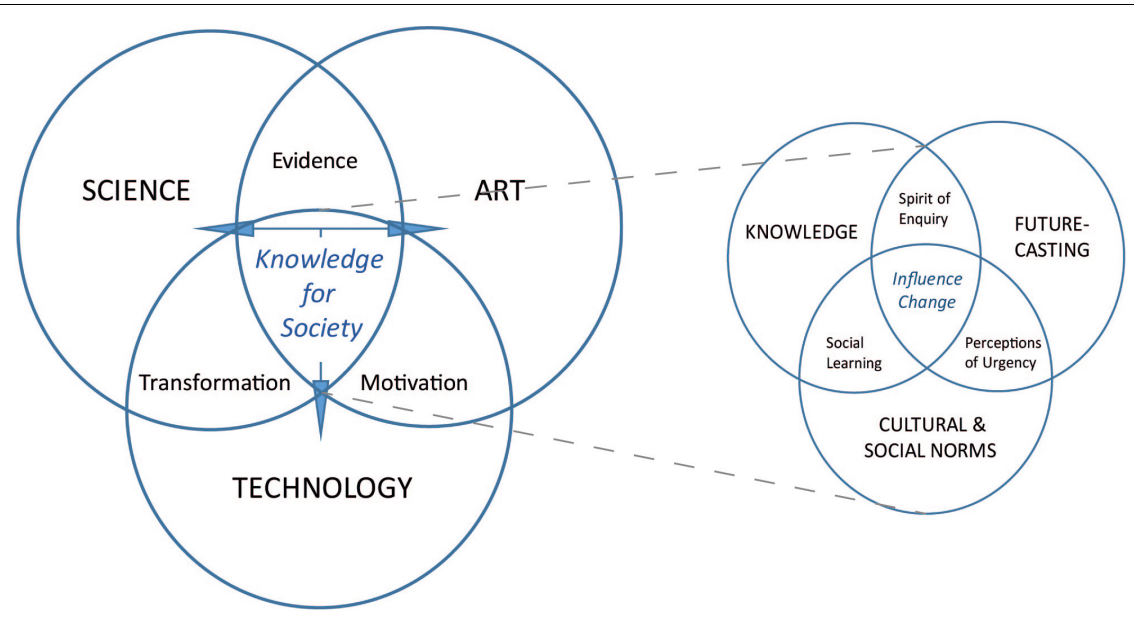

FIGURE 6 | A model of knowledge generation that is responsive to the needs of society and allows reciprocity and exchange between and within disciplines.

exchange, rupturing the engrained status quo of divisions across and between academia and society offers solutions spaces rather than dictates destinations.

While the literature and concepts discussed in this paper, as well as the case study, demonstrate transdisciplinary benefits, it must also be recognized that there are methodological and collaborative challenges necessary for such endeavors. This reality has stimulated critical reflection on practice and limitations in traditional disciplinary evaluation methods (e.g., Muller et al., 2015; van Mierlo and Beers, 2018) but also allowed space from reframing art-science intersections as 'shared encounters with politics and environmental change' (Gabrys and Yusoff, 2012). While there are two central themes that resonate within current art-science collaborative practice: (i) the ability to engage diverse publics (Gabrys and Yusoff, 2012; Lesen et al., 2016) and (ii) the ability to 'do' social, cultural and political work (Gibbs, 2014; Galafassi et al., 2018), there is evidence that expectations of artists and scientists may differ as a consequence of disparate training, methods, values, vocabulary, funding, and income (Lesen et al., 2016). If art-science collaborations are visualized on a spectrum, at the 'service mentality' end artists might take inspiration from science but not work directly with scientists, and likewise there might be scientists making art without direct contact with artists. At the other end of the continuum, integrated partnerships between artists and scientists have been gaining in popularity as an intellectual practice, however, disciplinary integration remains a difficult obstacle to overcome.

Nevertheless, within the sustainability and climate change arena, increasingly framed within the concept of the Anthropocene (Crutzen, 2006), integrated, co-designed and co-produced, challenge-led collaborations can provide the innovation needed to allow the visualization and realization of solutions and pathways to sustainability become more reachable from a local to global scale across social and political spectra (Reed and Abernethy, 2018). As Biermann et al. (2016) state 'The Anthropocene is now being used as a conceptual frame by different communities and in a variety of contexts to understand the evolving human-environment relationship.' The authors go on to state that '...the Anthropocene can be a useful conceptual frame only when it is viewed from a cross-scalar perspective that takes into account developments at local, regional and global levels, variant connections among these levels and issue domains, as well as societal inequality and injustice' (Biermann et al., 2016). The power of the Anthropocene concept, therefore, is in examining and amplifying (i) complex normative understanding (making pervasive inequalities more visible); and (ii) novel directions for better governance, from local to global (Biermann et al., 2016) including increasing centrality of actors from the whole myriad of social structures. This contextualized, localized and social understanding of the Anthropocene, sensitive to global inequalities and disparities, can contribute to new insights into global and local interconnectivities relevant to the delivery of the SDGs and other international conventions (e.g., the New Urban Agenda, Paris-COP21, and the Convention on Biological Diversity).

\section{CONCLUSION}

There is precedent for urging against modernist metaphors of 'building bridges' across disciplinary divides and instead for 'plunging into the river together, rather than attempting to bridge it' (Head, 2011) that supports the notion that insights from both the arts and sciences will be needed to overcome maladaptive practices by practitioners and society alike common in the Anthropocene. Art-science collaborations aim to transcend practices that compartmentalize knowledge, instead catalyzing innovations by cross-pollinating disciplinary processes and products (Leimbach and Armstrong, 2018). While art-science collaboration is often touted as 'transformative' resulting in changes in perspectives or insight by facilitating engagement with the public or with stakeholders and subjects of science, mechanisms that begin to measure this impactto-influence remain challenging (105). Quantitative methods (visitor numbers, citations, etc.) do not provide the data needed to determine the value and benefit of aesthetic engagement, 
while conventional qualitative evaluations are insufficient because they do not assess value beyond their disciplinary value structures. This research space opens several potential avenues of novel investigation in the future.

Studies have recognized that environmental issues and societies responses to them are in themselves a competitive space (Tiller et al., 2019). The process of understanding the need for significant systemic changes in practices, informed by scientific analysis of trends, acknowledging local knowledge and ways of knowing, and taking stock of social-ecological system constraints and opportunities for transformation is critical to the approach described in this paper. The multifaceted challenges of coastal and ocean sustainability cannot be addressed by science alone. While it is often easier to describe the problem rather than to agree on the actions that need to be taken in specific contexts to address those risks, the demand for innovative research and practices that 'think outside the box' - with new modalities of transdisciplinary action research that complement traditional disciplinary research is growing rapidly. There is an urgent need for new means of representation to convey the complexity of environmental change, and a growing recognition of the limited ability of science alone to influence policy change. Sustainability and climate science are the latest to acknowledge the urgency to rupture this status quo in order to enable action.

\section{DATA AVAILABILITY STATEMENT}

The datasets generated for this study are available on request to the corresponding author.

\section{ETHICS STATEMENT}

Written informed consent was obtained from the relevant individuals for the publication of any potentially identifiable images or data included in this article.

\section{REFERENCES}

Adger, W. N., Butler, C., and Walker-Springett, K. (2017). Moral reasoning in adaptation to climate change. Environ. Polit. 26, 371-390. doi: 10.1080/ 09644016.2017.1287624

Ajzen, I. (1985). "From intentions to actions: a theory of planned behavior," in Action Control. SSSP Springer Series in Social Psychology, eds J. Kuhl and J. Beckmann (Berlin: Springer). doi: 10.1016/j.addbeh.2005. 08.012

Audet, R. (2014). The double hermeneutic of sustainability transitions. Environ. Innov. Soc. Transit. 11, 46-49. doi: 10.1016/j.eist.2014.02.001

Ballantyne, A. G. (2016). Climate change communication: what can we learn from communication theory? Wiley Interdiscip. Rev. Clim. Chang. 7, 329-344. doi: 10.1002/wcc.392

Barry, A., Born, G., and Weszkalnys, G. (2008). Logics of interdisciplinarity. Econ. Soc. 37, 20-49. doi: 10.1080/03085140701760841

Bastien, S., and Holmarsdottir, H. B. (eds) (2017). “The Sustainable Development Goals and the Role of Youth-Driven Innovation for Social Change," in Youth as Architects of Social Change: Global Efforts to Advance YouthDriven Innovation, eds S. Bastien and H. B. Holmarsdottir (Cham: Springer International Publishing), 3-22. doi: 10.1007/978-3-319-66 275-6_1

\section{AUTHOR CONTRIBUTIONS}

SP: conceptualization, methodology, writing - original draft preparation, and writing - review and editing. ML: conceptualization, methodology, writing - original draft preparation, and writing - review and editing. HW: conceptualization, methodology, project administration, visualization, and writing - review and editing. LR and KT: conceptualization, funding acquisition, investigation, and methodology. MI: conceptualization and writing - review and editing. JM: data curation, formal analysis, investigation, and visualization.

\section{FUNDING}

The research reported on in this paper was funded in part by Future Earth Coasts, by East Carolina University (College of Fine Arts and Communication Research and Creative Activity Awards) and by the University of Wisconsin-Stevens Point (Research and Creative Activities Grant \#3218.07). Participation to workshops mentioned in the text benefited from a Marine Research Programme Networking and Travel Grant (NT/19/45) from the Marine Institute, Ireland and Brunel University London (QR-GCRF).

\section{ACKNOWLEDGMENTS}

The authors wish to thank Aoife Deane (MaREI) for her continued insight into project communication and impact, Dr. Ruth Brennan (Trinity College Dublin) for her support and assistance with the audio components of $\mathrm{CaW}$, and Keven Brunett for his contribution to numerous CaW exhibitions. In addition, the authors would like to thank the reviewers for their constructive comments on this manuscript.

Béné, C., Arthur, R., Norbury, H., Allison, E. H., Beveridge, M., Bush, S., et al. (2016). Contribution of fisheries and aquaculture to food security and poverty reduction: assessing the current evidence. World Dev. 79, 177-196. doi: 10.1016/ j.worlddev.2015.11.007

Benham, C. F., and Daniell, K. A. (2016). Putting transdisciplinary research into practice: a participatory approach to understanding change in coastal socialecological systems. Ocean Coast. Manag. 128, 29-39. doi: 10.1016/j.ocecoaman. 2016.04.005

Bennett, N. J. (2016). Using perceptions as evidence to improve conservation and environmental management. Conserv. Biol. 30, 582-592. doi: 10.1111/cobi. 12681

Bernstein, J. H. (2015). Transdisciplinarity: a review of its origins, development, and current issues. J. Res. Pract. 11:R1.

Bexell, M., and Jönsson, K. (2017). Responsibility and the United Nations', sustainable development goals. Forum Dev. Stud. 44, 13-29. doi: 10.1080/ 08039410.2016.1252424

Biermann, F., Bai, X., Bondre, N., Broadgate, W., Arthur Chen, C.-T., Dube, O. P., et al. (2016). Down to earth: contextualizing the anthropocene. Glob. Environ. Chang. 39, 341-350. doi: 10.1016/j.gloenvcha.2015.11.004

Blythe, J., Silver, J., Evans, L., Armitage, D., Bennett, N. J., Moore, M.-L., et al. (2018). The dark side of transformation: latent risks in contemporary sustainability discourse. Antipode 50, 1206-1223. doi: 10.1111/anti.12405 
Borja, A., Elliott, M., Uyarra, M. C., Carstensen, J., and Mea, M. (2017). Bridging the gap between policy and science in assessing the health status of marine ecosystems. Front. Mar. Sci. 4:32. doi: 10.3389/fmars.2017.00032

Born, G., and Barry, A. (2010). ART-SCIENCE: from public understanding to public experiment. J. Cult. Econ. 3, 103-119. doi: 10.1080/17530351003617610

Brandt, P., Ernst, A., Gralla, F., Luederitz, C., Lang, D. J., Newig, J., et al. (2013). A review of transdisciplinary research in sustainability science. Ecol. Econ. 92, 1-15. doi: 10.1016/j.ecolecon.2013.04.008

Brennan, R. E. (2018). Re-storying marine conservation: integrating art and science to explore and articulate ideas, visions and expressions of marine space. Ocean Coast. Manag. 162, 110-126. doi: 10.1016/J.OCECOAMAN.2018.01.036

Broadhurst, S. (2007). Digital Practices: Aesthetic and Neuroesthetic Approaches to Performance and Technology. New York, NY: Palgrave.

Brown, V. A. (2015). Utopian thinking and the collective mind: beyond transdisciplinarity. Futures 65, 209-216. doi: 10.1016/j.futures.2014.11.004

Brugnach, M., and Ingram, H. (2012). Ambiguity: the challenge of knowing and deciding together. Environ. Sci. Policy 15, 60-71. doi: 10.1016/j.envsci.2011.10. 005

Carew, A. L., and Wickson, F. (2010). The TD Wheel: a heuristic to shape, support and evaluate transdisciplinary research. Futures 42, 1146-1155. doi: 10.1016/j. futures.2010.04.025

Carnell, S., Cooper, K., Moss, R., Wilson, T. M., Walsh, P., Auman, H. J., et al. (2020). Vanishing Point. Available online at: http://www.vanishingpoint.net.au/ (accessed March 9, 2020).

Catching a Wave (2019). Catching a Wave at Art in the Anthropocene conference | Dublin | 7-9 June 2019. Available online at: https://www.catchingawave.org/ workshop-dublin-7-june-2019 (accessed March 31, 2020).

Chabay, I. (2015). "Narratives for a Sustainable Future: vision and Motivation for Collective Action," in Global Sustainability: Cultural Perspectives and Challenges for Transdisciplinary Integrated Research, ed. B. Werlen (Cham: Springer International Publishing), 51-61. doi: 10.1007/978-3-319-164 77-9_3

Claudet, J., Bopp, L., Cheung, W. W. L., Devillers, R., Escobar-Briones, E., Haugan, P., et al. (2020). A roadmap for using the UN Decade of ocean science for sustainable development in support of science, policy, and action. One Earth 2, 34-42. doi: 10.1016/j.oneear.2019.10.012

Comte, A., Pendleton, L. H., Bailly, D., and Quillérou, E. (2019). Conceptual advances on global scale assessments of vulnerability: informing investments for coastal populations at risk of climate change. Mar. Policy 99, 391-399. doi: 10.1016/j.marpol.2018.10.038

Cormier, R., and Elliott, M. (2017). SMART marine goals, targets and management - Is SDG 14 operational or aspirational, is 'Life Below Water' sinking or swimming? Mar. Pollut. Bull. 123, 28-33. doi: 10.1016/j.marpolbul. 2017.07.060

Cornell, S., Berkhout, F., Tuinstra, W., Tàbara, J. D., Chabay, I., de Wit, B., et al. (2013). Opening up knowledge systems for better responses to global environmental change. Environ. Sci. Policy 28, 60-70. doi: 10.1016/J.ENVSCI. 2012.11.008

Cox, D. (1991). Collaborations in art/science: renaissance teams. J. Biocommun. 18, $15-24$.

Cox, D. (2004). The art and science of visualization: metaphorical maps and cultural models. Technoetic Arts 2, 71-79.

Crutzen, P. J. (2006). "The 'Anthropocene," in Earth System Science in the Anthropocene, eds E. Ehlers and T. Krafft (Berlin: Springer), 13-18. doi: 10. 1007/3-540-26590-2_3

Cummings, S., Regeer, B., de Haan, L., Zweekhorst, M., and Bunders, J. (2018). Critical discourse analysis of perspectives on knowledge and the knowledge society within the Sustainable Development Goals. Dev. Policy Rev. 36, 727-742. doi: $10.1111 /$ dpr.12296

Custer, S., DiLorenzo, M., Masaki, T., Sethi, T., and Harutyunyan, A. (2018). Listening to Leaders 2018: Is Development Cooperation Tuned-in or Tone-Deaf? Williamsburg, VA: AidData at the College of William \& Mary.

da Costa, B., and Philip, K. (2008). Tactical Biopolitics: Art, Activism, and Technoscience. Cambridge, MA: MIT Press.

Defila, R., and Di Giulio, A. (2015). Integrating knowledge: challenges raised by the "Inventory of Synthesis.". Futures 65, 123-135. doi: 10.1016/j.futures.2014. 10.013
Dietz, S., and Neumayer, E. (2007). Weak and strong sustainability in the SEEA: concepts and measurement. Ecol. Econ. 61, 617-626. doi: 10.1016/j.ecolecon. 2006.09.007

Dow, K., Berkhout, F., and Preston, B. L. (2013). Limits to adaptation to climate change: a risk approach. Curr. Opin. Environ. Sustain. 5, 384-391. doi: 10.1016/ j.cosust.2013.07.005

Eldred, S. M. (2016). Art-science collaborations: change of perspective. Nature 537, 125-126. doi: 10.1038/nj7618-125a

Ensor, J., Forrester, J., and Matin, N. (2018). Bringing rights into resilience: revealing complexities of climate risks and social conflict. Disasters 42, S287S305. doi: 10.1111/disa.12304

Ensor, J., and Harvey, B. (2015). Social learning and climate change adaptation: evidence for international development practice. Wiley Interdiscip. Rev. Clim. Chang. 6, 509-522. doi: 10.1002/wcc.348

European Commission (2019). The EU Blue Economy Report. Luxembourg: Office of the European Union.

Fischer, F. (2006). Participatory governance as deliberative empowerment: the cultural politics of discursive space. Am. Rev. Public Adm. 36, 19-40. doi: 10.1177/0275074005282582

Fleming, L. E., Maycock, B., White, M. P., and Depledge, M. H. (2019). Fostering human health through ocean sustainability in the 21 st century. People Nat. 1, 276-283. doi: 10.1002/pan3.10038

Fredman, S., Kuosmanen, J., and Campbell, M. (2016). Transformative equality: making the sustainable development goals work for women. Ethics Int. Aff. 30, 177-187.

Freistein, K., and Mahlert, B. (2016). The potential for tackling inequality in the Sustainable Development Goals. Third World Q. 37, 2139-2155. doi: 10.1080/ 01436597.2016.1166945

Fukuda-Parr, S., and McNeill, D. (2019). Knowledge and Politics in Setting and Measuring the SDGs: introduction to Special Issue. Glob. Policy 10, 5-15. doi: 10.1111/1758-5899.12604

Future Earth Coasts (2018). Our Coastal Futures: Strategy for Research. Available online at: https://www.futureearthcoasts.org/our-coastal-futures/ (accessed June 28, 2019).

Future Earth Coasts (2020). InvestInBlue: What's Art got to do with it? Society and Sea conference | Greenwich | 6 \& 7 September 2018. Available online at: http://www.futureearthcoasts.org/society-and-the-sea-2018/ (accessed March $31,2020)$

Gabrys, J., and Yusoff, K. (2012). Arts, sciences and climate change: practices and politics at the threshold. Sci. Cult. 21, 1-24. doi: 10.1080/09505431.2010.550139

Galafassi, D., Kagan, S., Milkoreit, M., Heras, M., Bilodeau, C., Bourke, S. J., et al. (2018). 'Raising the temperature': the arts on a warming planet. Curr. Opin. Environ. Sustain. 31, 71-79. doi: 10.1016/j.cosust.2017. 12.010

Geels, F. W. (2011). The multi-level perspective on sustainability transitions: responses to seven criticisms. Environ. Innov. Soc. Transit. 1, 24-40. doi: 10 1016/j.eist.2011.02.002

Geels, F. W., McMeekin, A., Mylan, J., and Southerton, D. (2015). A critical appraisal of sustainable consumption and production research: the reformist, revolutionary and reconfiguration positions. Glob. Environ. Chang. 34, 1-12. doi: 10.1016/j.gloenvcha.2015.04.013

Ghosh, R. (2005). CODE: Collaborative Ownership and the Digital Economy. Cambridge, MA: MIT Press.

Gibbs, L. (2014). Arts-science collaboration, embodied research methods, and the politics of belonging: 'SiteWorks' and the Shoalhaven River, Australia. Cult. Geogr. 21, 207-227. doi: 10.1177/1474474013487484

Goyal, N., and Howlett, M. (2019). Who learns what in sustainability transitions? Environ. Innov. Soc. Transit. 34, 311-321. doi: 10.1016/j.eist.2019.09.002

Gurnon, D., Voss-Andreae, J., and Stanley, J. (2013). Integrating art and science in undergraduate education. PLoS Biol. 11:e1001491. doi: 10.1371/journal.pbio. 1001491

Haward, M. (2018). Plastic pollution of the world's seas and oceans as a contemporary challenge in ocean governance. Nat. Commun. 9:667. doi: 10. 1038/s41467-018-03104-3

Hawkins, H., Marston, S. A., Ingram, M., and Straughan, E. (2015). The art of socioecological transformation. Ann. Assoc. Am. Geogr. 105, 331-341. doi: 10. 1080/00045608.2014.988103 
Hayward, B., and Roy, J. (2019). Sustainable living: bridging the north-south divide in lifestyles and consumption debates. Annu. Rev. Environ. Resour. 44, 157-175.

Head, L. (2011). More than human, more than nature. Griffith Rev. 31:43. doi: $10.1017 /$ S0140525X10000191

Hoegh-Guldberg, O. (2015). Reviving the Ocean Economy: the case for action - 2015. Gland: WWF International, 60.

Horner, R., and Hulme, D. (2019). From international to global development: new geographies of 21st century development. Dev. Change 50, 347-378. doi: $10.1111 /$ dech. 12379

Huelsenbeck, M. (2012). Ocean-Based Food Security Threatened in a High CO2 World. Washington, DC: Oceana.

Huggins, R., and Clifton, N. (2011). Competitiveness, creativity, and place-based development. Environ. Plan. A 43, 1341-1362. doi: 10.1068/a43559

ICSU, and ISSC (2015). Review of the Sustainable Development Goals: The Science Perspective. Paris: International Council for Science (ICSU).

Ingram, M. (2011). Eliciting a response through art. Nat. Clim. Chang. 1, 133-134. doi: $10.1038 /$ nclimate 1140

Ingram, M. (2014). Washing urban water: diplomacy in environmental art in the. . Gend. Place Cult. 21, 105-122.

IPCC (2019). in Report on the Ocean and Cryosphere in a Changing Climate, eds H.-O. Portner, D. C. Roberts, V. Masson-Delmotte, P. Zhai, M. Tignor, E. Poloczanska, et al. (Geneva: IPCC).

Iqbal, I., and Pierson, C. (2017). A north-south struggle: political and economic obs tacles to sustainable development. Sustain. Dev. Law Policy 16:4.

Irwin, E. G., Culligan, P. J., Fischer-Kowalski, M., Law, K. L., Murtugudde, R., and Pfirman, S. (2018). Bridging barriers to advance global sustainability. Nat. Sustain. 1, 324-326. doi: 10.1007/s11625-018-0604-z

Jefferson, R., McKinley, E., Capstick, S., Fletcher, S., Griffin, H., and Milanese, M. (2015). Understanding audiences: making public perceptions research matter to marine conservation. Ocean Coast. Manag. 115, 61-70. doi: 10.1016/j. ocecoaman.2015.06.014

Klenk, N. L., and Meehan, K. (2017). Transdisciplinary sustainability research beyond engagement models: toward adventures in relevance. Environ. Sci. Policy 78, 27-35. doi: 10.1016/j.envsci.2017.09.006

Le Blanc, D. (2015). Towards integration at last? The sustainable development goals as a network of targets. Sustain. Dev. 23, 176-187. doi: 10.1002/sd.1582

Leach, J. (2005). "Being in between": art-science collaborations and a technological culture. Soc. Anal. Int. J. Soc. Cult. Pract. 49, 141-160.

Leimbach, T., and Armstrong, K. (2018). "Creative partnerships and cultural organisations: 'enabling' and 'situating' arts-science collaboration and collective learning," in Transdisciplinary Theory, Practice and Education: The Art of Collaborative Research and Collective Learning, eds D. Fam, L. Neuhauser, and P. Gibbs (Cham: Springer), 241-256. doi: 10.1007/978-3-319-93743-4_16

Leiserowitz, A. A., Kates, R. W., and Parris, T. M. (2006). Sustainability values, attitudes, and behaviors: a review of multinational and global trends. Annu. Rev. Environ. Resour. 31, 413-444. doi: 10.1146/annurev.energy.31.102505.133552

Lemke, W. (2016). The role of sport in achieving the sustainable development goals. UN Chron. 53, 6-9. doi: 10.18356/7260830a-en

Lesen, A. E., Rogan, A., and Blum, M. J. (2016). Science communication through art: objectives, challenges, and outcomes. Trends Ecol. Evol. 31, 657-660. doi: 10.1016/j.tree.2016.06.004

Lim, M., Sogaard Jorgensen, P., and Wyborn, C. (2018). Reframing the sustainable development goals to achieve sustainable development in the Anthropocene - a systems approach. Ecol. Soc. 23:22. doi: 10.5751/ES-10182-230322

Liverman, D. M. (2018). Geographic perspectives on development goals: constructive engagements and critical perspectives on the MDGs and the SDGs. Dialogues Hum. Geogr. 8, 168-185. doi: 10.1177/2043820618780787

Malina, R. F. (2001). The New Leonardos. Leonardo 34, 293-294. doi: 10.1162/ 00240940152549186

Marques, S., Steiner, A. Q., and de Almeida Medeiros, M. (2016). Assessing the performance of the Aichi Biodiversity Targets in Brazil: a test using two regional-scale indices related to coastal and marine ecosystem conservation. Mar. Policy 67, 130-138. doi: 10.1016/j.marpol.2016.01.030

Mayer, A., Shelley, T. O., Chiricos, T., and Gertz, M. (2017). Environmental risk exposure, risk perception, political ideology and support for climate policy. Sociol. Focus 50, 1-20. doi: 10.1080/00380237.2017.131 2855
McAfee, D., Doubleday, Z. A., Geiger, N., and Connell, S. D. (2019). Everyone loves a success story: optimism inspires conservation engagement. Bioscience 69, 274-281. doi: 10.1093/biosci/biz019

Miller, T. R., Wiek, A., Sarewitz, D., Robinson, J., Olsson, L., Kriebel, D., et al. (2014). The future of sustainability science: a solutions-oriented research agenda. Sustain. Sci. 9, 239-246. doi: 10.1007/s11625-018-0599-5

Moser, S. C. (2016). Reflections on climate change communication research and practice in the second decade of the 21st century: what more is there to say? Wiley Interdiscip. Rev. Clim. Chang. 7, 345-369. doi: 10.1002/wcc.403

Muller, L., Bennett, J., Froggett, L., and Bartlett, V. (2015). "Understanding third space: evaluating art-science collaboration," in Proceedings of the 21st International Symposium on Electronic Art, Vancouver.

Neumann, B., Ott, K., and Kenchington, R. (2017). Strong sustainability in coastal areas: a conceptual interpretation of SDG 14. Sustain. Sci. 12, 1019-1035. doi: 10.1007/s11625-017-0472-y

Norström, A. V., Cvitanovic, C., Löf, M. F., West, S., Wyborn, C., Balvanera, P., et al. (2020). Principles for knowledge co-production in sustainability research. Nat. Sustain. 3, 182-190.

O'Connor, G., and Stevens, C. (2018). Studioantarctica: edition. Leonardo 51, $57-58$.

Oliver, K., and Boaz, A. (2019). Transforming evidence for policy and practice: creating space for new conversations. Palgrave Commun. 5:60.

Olsen, E., Fay, G., Gaichas, S., Gamble, R., Lucey, S., and Link, J. S. (2016). Ecosystem Model Skill Assessment. Yes We Can! PLoS One 11:e0146467. doi: 10.1371/journal.pone.0146467

Paavola, J., and Adger, W. N. (2006). Fair adaptation to climate change. Ecol. Econ. 56, 594-609. doi: 10.1016/j.ecolecon.2005.03.015

Patterson, J., Thaler, T., Hoffmann, M., Hughes, S., Oels, A., Chu, E., et al. (2018). Political feasibility of $1.5^{\circ} \mathrm{C}$ societal transformations: the role of social justice. Curr. Opin. Environ. Sustain. 31, 1-9. doi: 10.1016/j.cosust.2017.11.002

Pearce, C., Diamond, S., and Beam, M. (2003). BRIDGES I: interdisciplinary collaboration as practice. Leonardo 36, 123-128. doi: 10.1162/ 002409403321554189

Pelling, M., O'Brien, K., and Matyas, D. (2015). Adaptation and transformation. Clim. Change 133, 113-127.

Plag, H. P. (ed.) (2018). Workshop Report "Proceedings of the Implementing and Monitoring the Sustainable Development Goals in the Caribbean: The Role of the Ocean" January 17-19, 2018. Saint Vincent: GEOSS Science and Technology Stakeholder Network (GSTSN).

Popa, F., Guillermin, M., and Dedeurwaerdere, T. (2015). A pragmatist approach to transdisciplinarity in sustainability research: from complex systems theory to reflexive science. Futures 65, 45-56. doi: 10.1016/j.futures.2014.02.002

Ramesh, R., Chen, Z., Cummins, V., Day, J., D’Elia, C., Dennison, B., et al. (2015). Land-Ocean Interactions in the Coastal Zone: past, present \& future. Anthropocene 12, 85-98. doi: 10.1016/j.ancene.2016.01.005

Randers, J., Rockstrom, J., Stoknes, P. E., Goluke, U., Collste, D., and Cornell, S. (2018). Transformation is Feasible - How to Achieve the Sustainable Development Goals within Planetary Boundaries. Kräftriket: Stockholm Resilience Center.

Reed, M. G., and Abernethy, P. (2018). Facilitating co-production of transdisciplinary knowledge for sustainability: working with canadian biosphere reserve practitioners. Soc. Nat. Resour. 31, 39-56. doi: 10.1080/08941920.2017.1383545

Reed, M. S., Evely, A. C., Cundill, G., Fazey, I., Glass, J., Laing, A., et al. (2010). What is social learning? Ecol. Soc. 15:r1.

Sachs, J., Schmidt-Traub, G., Kroll, C., Lafortune, G., and Fuller, G. (2018). SDG Index and Dashboards Report 2018. New York, NY: Bertelsmann Stiftung and Sustainable Development Solutions Network (SDSN).

Scherer, L., Behrens, P., de Koning, A., Heijungs, R., Sprecher, B., and Tukker, A. (2018). Trade-offs between social and environmental Sustainable Development Goals. Environ. Sci. Policy 90, 65-72. doi: 10.1016/j.envsci.2018.10.002

Scheyvens, R., Banks, G., and Hughes, E. (2016). The private sector and the SDGs: the need to move beyond 'Business as Usual.'. Sustain. Dev. 24, 371-382. doi: $10.1002 /$ sd. 1623

Schneider, F., Giger, M., Harari, N., Moser, S., Oberlack, C., Providoli, I., et al. (2019). Transdisciplinary co-production of knowledge and sustainability transformations: three generic mechanisms of impact generation. Environ. Sci. Policy 102, 26-35. doi: 10.1016/j.envsci.2019.08.017 
Scoones, I., Stirling, A., Abrol, D., Atela, J., Charli-Joseph, L., Eakin, H., et al. (2020). Transformations to sustainability: combining structural, systemic and enabling approaches. Curr. Opin. Environ. Sustain. 42, 65-75. doi: 10.1016/j. cosust.2019.12.004

Shi, J., Visschers, V. H. M., Siegrist, M., and Arvai, J. (2016). Knowledge as a driver of public perceptions about climate change reassessed. Nat. Clim. Chang. 6, 759-762.

Sleigh, C., and Craske, S. (2017). Art and science in the UK: a brief history and critical reflection. Interdiscip. Sci. Rev. 42, 313-330. doi: 10.1080/03080188. 2017.1381223

Snow, C. P. (1956). The Two Cultures. Cambridge: Cambridge University Press.

Soosalu, G., Henwood, S., and Deo, A. (2019). Head, heart, and gut in decision making: development of a multiple brain preference questionnaire. SAGE Open 9, 1-17. doi: 10.1177/2158244019837439

Stafford-Smith, M., Griggs, D., Gaffney, O., Ullah, F., Reyers, B., Kanie, N., et al. (2017). Integration: the key to implementing the Sustainable Development Goals. Sustain. Sci. 12, 911-919. doi: 10.1007/s11625-0160383-3

Stevens, C., and Kanie, N. (2016). The transformative potential of the Sustainable Development Goals (SDGs). Int. Environ. Agreements Polit. Law Econ. 16, 393-396. doi: 10.1007/s10784-016-9324-y

Straughan, E., and Dixon, D. (2014). Rhythm and mobility in the inner and outer hebrides: archipelago as art-science research site. Mobilities 9, 452-478. doi: 10.1080/17450101.2013.844926

Swain, R. B. (2018). "A critical analysis of the sustainable development goals," in Handbook of Sustainability Science and Research. (World Sustainability Series, ed. W. Leal Filho (Cham: Springer), 341-355. doi: 10.1093/heapro/ day036

Tiller, R., Arenas, F., Galdies, C., Leitão, F., Malej, A., Romera, B. M., et al. (2019). Who cares about ocean acidification in the Plasticene? Ocean Coast. Manag. 174, 170-180. doi: 10.1016/j.ocecoaman.2019.03.020

Trondle, M., Greenwood, S., Ramakrishnan, C., Tschacher, W., Kirchberg, V., Wintzerith, S., et al. (2019). The Entanglement of Arts and Sciences: On the Transaction Costs of Transdisciplinary Research Settings. Available online at: https://www.researchcatalogue.net/view/12219/12220/0/8973 (accessed August 22, 2019).

UNEP (2019). Frontiers 2018/19 Emerging Issues of Environmental Concern. Nairobi: United Nations Environment Programme.

United Nations (2015). Transforming Our World: The 2030 Agenda for Sustainable Development. New York, NY: United Nations.

van der Hel, S. (2016). New science for global sustainability? The institutionalisation of knowledge co-production in Future Earth. Environ. Sci. Policy 61, 165-175. doi: 10.1016/j.envsci.2016.03.012 van der Vaart, G., van Hoven, B., and Huigen, P. P. P. (2018). The role of the arts in coping with place change at the coast. Area 50, 195-204. doi: 10.1111/area. 12417

van Mierlo, B., and Beers, P. J. (2018). Understanding and governing learning in sustainability transitions: a review. Environ. Innov. Soc. Transit. 34, 255-269. doi: 10.1016/j.eist.2018.08.002

Villarrubia-Gómez, P., Cornell, S. E., and Fabres, J. (2018). Marine plastic pollution as a planetary boundary threat - The drifting piece in the sustainability puzzle. Mar. Policy 96, 213-220. doi: 10.1016/j.marpol.2017.11.035

Visbeck, M. (2018). Ocean science research is key for a sustainable future. Nat. Commun. 9:690. doi: 10.1038/s41467-018-03158-3

Weber, O. (2018). The Financial Sector and the SDGs: Interconnections and Future Directions. Waterloo, ON: Centre for International Governance Innovation.

Wehn, U., and Montalvo, C. (2018). Knowledge transfer dynamics and innovation: behaviour, interactions and aggregated outcomes. J. Clean. Prod. 171, S56-S68. doi: 10.1016/J.JCLEPRO.2016.09.198

Whitehead, F. (2018). "Civic experiments: tactics for praxis," in Art and Future: Energy, Climate, Cultures, ed. P. Stupples (Newcastle upon Tyne: Cambridge Scholars Publishing), 133-144.

Wilson, S. (2002). Information Arts Intersections of Art, Science, and Technology. Cambridge, NY: MIT Press.

Woodward, K., Jones, J. P., Vigdor, L., Marston, S. A., Hawkins, H., and Dixon, D. P. (2015). One Sinister Hurricane: Simondon and Collaborative Visualization. Ann. Assoc. Am. Geogr. 105, 496-511. doi: 10.1080/00045608.2015.101 8788

Zafeirakopoulos, M., and van der Bijl-Brouwer, M. (2018). Exploring the transdisciplinary learning experiences of innovation professionals. Technol. Innov. Manag. Rev. 8, 50-59.

Zareie, B., and Jafari Navimipour, N. (2016). The impact of electronic environmental knowledge on the environmental behaviors of people. Comput. Human Behav. 59, 1-8. doi: 10.1016/j.chb.2016.01.025

Conflict of Interest: The authors declare that the research was conducted in the absence of any commercial or financial relationships that could be construed as a potential conflict of interest.

Copyright (๑) 2020 Paterson, Le Tissier, Whyte, Robinson, Thielking, Ingram and McCord. This is an open-access article distributed under the terms of the Creative Commons Attribution License (CC BY). The use, distribution or reproduction in other forums is permitted, provided the original author(s) and the copyright owner(s) are credited and that the original publication in this journal is cited, in accordance with accepted academic practice. No use, distribution or reproduction is permitted which does not comply with these terms. 